\title{
Article \\ Oral Cancer Knowledge and Awareness among Patients Referred to a University Dental Hospital in North Cyprus
}

\author{
Mujgan Firincioglulari ${ }^{1, *}$, Secil Aksoy ${ }^{2}$ and Kaan Orhan ${ }^{3,4,5}$ \\ 1 Department of Dentomaxillofacial Radiology, Faculty of Dentistry, Final International University, \\ Nicosia 99010, Cyprus \\ 2 Department of Dentomaxillofacial Radiology, Faculty of Dentistry, Near East University, Nicosia 99138, Cyprus; \\ secil.aksoy@neu.edu.tr \\ 3 Department of Dentomaxillofacial Radiology, Faculty of Dentistry, Ankara University, Ankara 06100, Turkey; \\ knorhan@dentistry.ankara.edu.tr \\ 4 Medical Design Application and Research Center (MEDITAM), Ankara University, Ankara 06100, Turkey \\ 5 Department of Dental and Maxillofacial Radiodiagnostics, Medical University of Lublin, 20-081 Lublin, Poland \\ * Correspondence: mujgan.gunduz@final.edu.tr
}

\section{check for}

updates

Citation: Firincioglulari, M.; Aksoy,

S.; Orhan, K. Oral Cancer Knowledge and Awareness among Patients Referred to a University Dental Hospital in North Cyprus. Appl. Sci. 2022, 12, 192. https://doi.org/ 10.3390/app12010192

Academic Editors: Mohammad Khursheed Alam, Mohammad Amjad Kamal and Kumar

Chandan Srivastava

Received: 10 November 2021

Accepted: 22 December 2021

Published: 25 December 2021

Publisher's Note: MDPI stays neutral with regard to jurisdictional claims in published maps and institutional affiliations.

Copyright: (C) 2021 by the authors. Licensee MDPI, Basel, Switzerland. This article is an open access article distributed under the terms and conditions of the Creative Commons Attribution (CC BY) license (https:// creativecommons.org/licenses/by/ $4.0 /)$.

\begin{abstract}
Public knowledge about oral cancer may help to prevent and detect the disease at an early stage. This study aimed to evaluate the awareness and knowledge levels on oral cancer symptoms and risk factors among patients attending a faculty of dentistry in North Cyprus. A total of 250 adult dental patients participated voluntarily in a self-administered questionnaire. The questionnaire included questions on sociodemographic profile, oral cancer awareness, and knowledge. A total of $54.8 \%$ of the participants were male and $91.2 \%$ of the participants had a high school diploma and above education. Most participants were knowledgeable about oral cancer symptoms and a majority of them identified oral ulceration (64\%). Tobacco cessation was the most selected option for protecting from oral cancer $(79.6 \%)$. Significant differences were found between genders in current smokers, past tobacco users, alcohol users, and HPV awareness questions $(p<0.05)$. Furthermore, awareness and knowledge questions were compared between smoker and non-smoker participants and significant differences were found in the answers of 'alcohol may cause mouth cancer' and 'quit tobacco use to prevent oral cancer' $(p<0.05)$. This study showed that most of the participants were aware that tobacco cessation reduces the risk of oral cancer. The survey results showed that patients in North Cyprus are generally aware of the risk of tobacco-related oral cancer, but they demonstrate lower knowledge about other risk factors.
\end{abstract}

Keywords: oral cancer; awareness; risk factors; attitudes; survey; dental patients

\section{Introduction}

Patients who are diagnosed with oral cancer display an exclusive set of challenging, sophisticated, and multidisciplinary clinical issues, and their survival rate and quality of life may be improved by early diagnosis [1]. Oral cavity cancer is one of the most common malignancies, not only in developing countries but also in the evolved world [2]. According to World Health Organization's (WHO) World Cancer Report 2014, oropharyngeal and oral cavity cancers are the seventh most frequently diagnosed cancers and are the ninth malignancy in terms of mortality in the world [3]. The annual estimation of oral cancer incidence is around 275,000 and pharyngeal cancer incidence is around 130,300 excluding nasopharynx, and two-thirds of these cases occur in developing countries [4].

Risk factors of oral cancer may differ in specific cultural and socioeconomic populations. Tobacco and alcohol consumption are the most compelling risk factors for the development of oral cavity cancer. The synergetic effect of tobacco and alcohol increases the oral cancer risk about 24-fold [5]. Oral cancers are diagnosed generally in patients between the ages of 55 and 64 years, and men exhibit a greater risk than women. In addition to consumption of alcohol and tobacco, other risk factors including betel quid chewing, 
low consumption of fruits and vegetables, excessive exposure to sunlight, and human papilloma virus infection are associated with large relative risks [6]. The way of living is an important risk factor for oral cancers, therefore the motivation of the patients' has an important role for awareness of oral cancer to adjust their behavior and lessen their chance of getting cancer [7].

In the earliest stage of oral cancer, most patients are asymptomatic. Lesions might be barely visible in the early stage and the physician may not notice it on routine examination. However, patients may show some symptoms, such as nonspecific pain, tooth mobility, bleeding, difficulty while speaking, dysphagia, pain during swallowing, ear pain, sensory and motor nerve deficits, mass lesions, or cervical lymphadenopathy [8].

Early periods of oral cancer which are localized stages are noticed at the rate of $30 \%$. If these lesions are noticed at localized stages, survival rates could be raised by $50 \%$. Even if the treatment has succeeded, usually the quality of life severely decreases. Treatment of oral cancers can vary as follows: radiation, surgery, and chemotherapy. Treatments can usually inflict physical harm, lead to tooth destruction, and also can cause salivary gland problems and other head and neck tissue damage [9].

Previous researchers have shown that a lack of public awareness about the signs, symptoms, and risk factors of oral cancer can lead to delayed diagnosis and insufficient prognosis $[10,11]$. Improvement in the knowledge about signs, symptoms, and early detection of oral cancer among people could help the prevention, early detection, and improved prognosis of the disease [12]. Dentistry faculties have a developmental function and play a significant role in educating patients about oral cancer. To the best of our knowledge, there are no previous oral cancer awareness survey reports in North Cyprus. It is hoped that the outcomes of this survey may establish the foundation of the North Cyprus database aimed at identifying the awareness and knowledge of oral cancer among dental patients. Therefore, the purpose of this study was to evaluate the level of public knowledge about signs, symptoms, knowledge, and risk factors of oral cancer among dental patients who were referred to a university dental hospital in North Cyprus.

\section{Materials and Methods}

In this study, we used probability sampling as a simple random sampling method (RAND). The sample choice is made at random, which guarantees that each member of the population will have the same probability of selection and inclusion in the sample group. Random sampling gives patients within a stratum an equal probability of being sampled. In total, 250 adult dental patients participated voluntarily in a self-administered questionnaire. The study was approved by Near East University, Faculty of Medicine Ethical Review Board (IRB-/2020/79-1101). All procedures performed in studies involving human participants were under the ethical standards of the institutional and/or national research committee and with the 1964 Helsinki declaration and its later amendments or comparable ethical standards. A self-administered multiple-choice questionnaire was used, which was prepared from a pretested questionnaire that has been administered in similar studies [13-15]. Near East University Faculty of Dentistry is the sole dental reference point where all dental subjects refer. When patients came for examination, they were informed that they could withdraw at any time and that their responses would be anonymous, and were informed about the questionnaire and all of their potential participant questions were answers, such as: "Do I have to do the questionnaire?"; "How long is the questionnaire?"; "Can anyone see my answers?"; "What is the survey for?"; and "Do I have to answer it right now?". Completing time for the questionnaire was estimated as 8 to $10 \mathrm{~min}$.

The questionnaire had two aims: (1) to figure out the risk factor prevalence in the population considered (2) and their cancer awareness. Thus, the questionnaire consisted of sociodemographic factors such as age, gender, and educational background, which also consisted of smoking and drinking habits awareness, general knowledge of oral cancer, knowledge of signs/symptoms, and risk factors for oral cancer. The questionnaire also consisted of two extended educational questions, the first one was about if their healthcare 
providers educate them about oral cancer and the association between HPV and oral cancer. The knowledgeability evaluation included three questions according to the awareness of alcohol and oral cancer, signs of oral cancer, and behaviors that may stop mouth cancer.

Surveys were collected by the front desk staff and the data were then exported into Excel (Microsoft Corporation, Seattle, WA, USA). For the aim of the study, smoking cigarettes, cigars, pipes, and e-cigarettes were classified as 'smoking tobacco', and chewing tobacco as using snuff was categorized under 'smokeless tobacco'.

Educational levels were categorized as I = (no schooling+ grades 1 to 12$)$, II = (high school diploma and above).

\section{Statistical Analysis}

Responses obtained from this survey study were performed descriptively. All responses were presented in the form of frequencies and percentages. Comparisons were made by using the chi-square test. All statistical analyses were performed with SPSS for Windows version 15.0 (SPSS Inc., Chicago, IL, USA). The significance level was set at $p<0.05$.

\section{Results}

A total of $54.8 \%(137 / 250)$ of the participants were male and $45.2 \%(113 / 250)$ of the participants were female; $92 \%(230 / 250)$ had a high school diploma and above education.

While 59.6\% (149/250) of the participants did not smoke now, 51.6\% (129/250) of them stated that they had smoked in the past. Daily consumption of smoking patients: $4.8 \%$ of them consumed at least five cigarettes, 15.6\% used 5-14 cigarettes, $13.6 \%$ consumed 15-29 cigarettes, and $2 \%$ of the smoking patients consumed more than 30 cigarettes. Only just one patient currently used smokeless tobacco.

Twenty-two percent of the participants tried to stop using tobacco products during the past 12 months. Furthermore, 50.4\% of the participants stated that no one was smoking in their house and $42.4 \%$ of them said there was daily tobacco consumption in their house.

A total of 55.6\% (139/250) of the participants did not use alcohol; the most frequent use was determined as per week at the rate of $29.2 \%(73 / 115)$.

While $87.2 \%$ of the participants considered tobacco use as a risk factor for oral cancer, this rate droped to $65.6 \%$ for alcohol use.

A mouth sore that does not heal (64\%) and abnormal mass/lump in the mouth $(59.2 \%)$ were detected at the highest rates as symptoms of oral cancer, and the percentages of other symptoms followed by white/red patch in the mouth $(41.6 \%)$, difficulty chewing/swallowing (40\%), and slow change in voice quality (34.4\%).

Stopping tobacco use was the most common option to prevent oral cancer $(79.6 \%)$, the prevalence of other actions was quitting alcohol use $(66.4 \%)$, avoiding contact with secondhand smoke (37.6\%), brushing and flossing your teeth twice/day (50.8\%), and telling your dentist when your denture(s) do not fit well $(23.3 \%)$.

In total, $62.4 \%$ of the participants stated that they were not getting any education about mouth cancer by their healthcare and $63.6 \%$ of all participants implied that their healthcare provider did not tell them that human papilloma virus (HPV) can cause mouth cancer.

A comparison of these answers according to gender can be seen in Table 1. Significant differences were found between genders in current smokers, past tobacco users, alcohol users, and HPV awareness questions. Female patients answered 'no' to these questions $(p<0.05)$.

Survey questions were compared between the currently smoking and non-smoker participants in Table 2. As a result, the rate of 'yes' answers to alcohol may cause mouth cancer and quit tobacco use was significantly higher in current smokers than non-smokers $(p<0.05)$. There was also no significant difference between alcohol users and nonalcohol users (Table 3). 
Table 1. Comparison of survey questions according to gender. * shows statistical significance $(p<0.05)$.

\begin{tabular}{|c|c|c|c|c|c|}
\hline & \multicolumn{4}{|c|}{ Gender } & \multirow{3}{*}{$p$-Value } \\
\hline & \multicolumn{2}{|c|}{ Male } & \multicolumn{2}{|c|}{ Female } & \\
\hline & Yes & No & Yes & No & \\
\hline Currently smoking & $46.7 \%$ & $53.3 \%$ & $32.7 \%$ & $67.3 \%$ & $0.028 *$ \\
\hline Used tobacco in the past & $59.7 \%$ & $40.3 \%$ & $43.8 \%$ & $56.3 \%$ & $0.015^{*}$ \\
\hline Smokeless tobacco & $0.7 \%$ & $99.3 \%$ & 0 & $100 \%$ & 1.00 \\
\hline Tried to stop using tobacco & $26.3 \%$ & $73.7 \%$ & $17.0 \%$ & $83.0 \%$ & 0.092 \\
\hline Tobacco may cause mouth cancer & $87.5 \%$ & $12.5 \%$ & $87.6 \%$ & $12.4 \%$ & 1.00 \\
\hline Alcohol use & $54.7 \%$ & $45.3 \%$ & $31.9 \%$ & $68.1 \%$ & $0.001 *$ \\
\hline Alcohol may cause mouth cancer & $65.4 \%$ & $34.6 \%$ & $66.4 \%$ & $33.6 \%$ & 0.894 \\
\hline Difficulty chewing/swallowing as a symptom of oral cancer & $38.0 \%$ & $62.0 \%$ & $42.5 \%$ & $57.5 \%$ & 0.517 \\
\hline A mouth sore that does not heal as a symptom of oral cancer & $66.4 \%$ & $33.6 \%$ & $61.1 \%$ & $38.9 \%$ & 0.428 \\
\hline Abnormal mass/lump in the mouth as a symptom of oral cancer & $59.1 \%$ & $40.9 \%$ & $59.3 \%$ & $40.7 \%$ & 1.00 \\
\hline White/red patch in the mouth as a symptom of oral cancer & $35.8 \%$ & $64.2 \%$ & $48.7 \%$ & $51.3 \%$ & 0.053 \\
\hline The slow change in voice quality as a symptom of oral cancer & $29.9 \%$ & $70.1 \%$ & $39.8 \%$ & $60.2 \%$ & 0.110 \\
\hline Quit tobacco use to prevent oral cancer & $75.2 \%$ & $24.8 \%$ & $85.9 \%$ & $15.0 \%$ & 0.060 \\
\hline Quit alcohol use to prevent oral cancer & $65.7 \%$ & $34.3 \%$ & $67.3 \%$ & $32.7 \%$ & 0.893 \\
\hline Avoid contact with secondhand smoke to prevent oral cancer & $34.3 \%$ & $65.7 \%$ & $41.6 \%$ & $58.4 \%$ & 0.241 \\
\hline $\begin{array}{l}\text { Brush and floss your teeth twice/day to prevent oral cancer to } \\
\text { prevent oral cancer }\end{array}$ & $51.1 \%$ & $48.9 \%$ & $50.4 \%$ & $49.6 \%$ & 1.00 \\
\hline $\begin{array}{l}\text { Telling your dentist when your dentures do not fit well to prevent } \\
\text { oral cancer }\end{array}$ & $23.4 \%$ & $76.6 \%$ & $22.1 \%$ & $77.9 \%$ & 0.880 \\
\hline Education about oral cancer & $40.1 \%$ & $59.9 \%$ & $33.9 \%$ & $66.1 \%$ & 0.357 \\
\hline Education about human papilloma virus and oral cancer & $42.3 \%$ & $57.7 \%$ & $29.2 \%$ & $70.8 \%$ & $0.035 *$ \\
\hline
\end{tabular}

Table 2. Statistical analysis of survey questions according to the current use of cigarettes. ${ }^{*}$ shows statistical significance $(p<0.05)$.

\begin{tabular}{|c|c|c|c|c|}
\hline & & \multicolumn{3}{|c|}{ Currently Smoking } \\
\hline & & Yes & No & $p$-value \\
\hline \multirow{2}{*}{ Tobacco may cause mouth cancer } & Yes & $88 \%$ & $87.2 \%$ & \multirow{2}{*}{1.00} \\
\hline & No & $12 \%$ & $12.8 \%$ & \\
\hline \multirow{2}{*}{ Alcohol may cause mouth cancer } & Yes & $74.3 \%$ & $60.1 \%$ & \multirow{2}{*}{$0.022 *$} \\
\hline & No & $25.7 \%$ & $39.9 \%$ & \\
\hline \multirow{2}{*}{ Difficulty chewing/swallowing as a symptom of oral cancer } & Yes & $37.6 \%$ & $41.6 \%$ & \multirow{2}{*}{0.599} \\
\hline & No & $62.4 \%$ & $58.4 \%$ & \\
\hline \multirow{2}{*}{ A mouth sore that does not heal as a symptom of oral cancer } & Yes & $65.3 \%$ & $63.1 \%$ & \multirow{2}{*}{0.789} \\
\hline & No & $34.7 \%$ & $36.9 \%$ & \\
\hline \multirow{2}{*}{ Abnormal mass/lump in the mouth as a symptom of oral cancer } & Yes & $54.5 \%$ & $62.4 \%$ & \multirow{2}{*}{0.238} \\
\hline & No & $45.5 \%$ & $37.6 \%$ & \\
\hline \multirow{2}{*}{ White/red patch in the mouth as a symptom of oral cancer } & Yes & $38.6 \%$ & $43.6 \%$ & \multirow{2}{*}{0.437} \\
\hline & No & $61.4 \%$ & $56.4 \%$ & \\
\hline \multirow{2}{*}{ The slow change in voice quality as a symptom of oral cancer } & Yes & $31.7 \%$ & $36.2 \%$ & \multirow{2}{*}{0.499} \\
\hline & No & $68.3 \%$ & $63.8 \%$ & \\
\hline
\end{tabular}


Table 2. Cont.

\begin{tabular}{|c|c|c|c|c|}
\hline & & \multicolumn{3}{|c|}{ Currently Smoking } \\
\hline & & Yes & No & $p$-value \\
\hline \multirow{2}{*}{ Quit tobacco use to prevent oral cancer } & Yes & $86.1 \%$ & $75.2 \%$ & \multirow{2}{*}{0.038 * } \\
\hline & No & $13.9 \%$ & $24.8 \%$ & \\
\hline \multirow{2}{*}{ Quit alcohol use to prevent oral cancer } & Yes & $71.3 \%$ & $63.1 \%$ & \multirow{2}{*}{0.219} \\
\hline & No & $28.7 \%$ & $36.9 \%$ & \\
\hline \multirow{2}{*}{ Avoid contact with secondhand smoke to prevent oral cancer } & Yes & $40.6 \%$ & $35.6 \%$ & \multirow{2}{*}{0.428} \\
\hline & No & $59.4 \%$ & $64.4 \%$ & \\
\hline \multirow{2}{*}{ Brush and floss your teeth twice/day to prevent oral cancer } & Yes & $47.5 \%$ & $53.0 \%$ & \multirow{2}{*}{0.440} \\
\hline & No & $52.5 \%$ & $47.0 \%$ & \\
\hline \multirow{2}{*}{$\begin{array}{l}\text { Telling your dentist when your dentures do not fit well to } \\
\text { prevent oral cancer }\end{array}$} & Yes & $17.8 \%$ & $26.2 \%$ & \multirow{2}{*}{0.128} \\
\hline & No & $82.2 \%$ & $73.8 \%$ & \\
\hline \multirow{2}{*}{ Education about oral cancer } & Yes & $38.6 \%$ & $36.5 \%$ & \multirow{2}{*}{0.790} \\
\hline & No & $61.4 \%$ & $63.5 \%$ & \\
\hline \multirow{2}{*}{ Education about human papilloma virus and oral cancer } & Yes & $37.6 \%$ & $35.6 \%$ & \multirow{2}{*}{0.789} \\
\hline & No & $62.4 \%$ & $64.4 \%$ & \\
\hline
\end{tabular}

Table 3. Statistical analysis of survey questions according to the current use of alcohol. Bold shows statistical significance $(p<0.05)$.

\begin{tabular}{|c|c|c|c|c|}
\hline & & \multicolumn{3}{|c|}{ Alcohol } \\
\hline & & Yes & No & $p$-Value \\
\hline \multirow{2}{*}{ Tobacco may cause mouth cancer } & Yes & $88.3 \%$ & $87.0 \%$ & \multirow{2}{*}{0.848} \\
\hline & No & $11.7 \%$ & $13.0 \%$ & \\
\hline \multirow{2}{*}{ Alcohol may cause mouth cancer } & Yes & $64.0 \%$ & $67.4 \%$ & \multirow{2}{*}{0.593} \\
\hline & No & $36.0 \%$ & $32.6 \%$ & \\
\hline \multirow{2}{*}{ Difficulty chewing/swallowing as a symptom of oral cancer } & Yes & $37.8 \%$ & $41.7 \%$ & \multirow{2}{*}{0.604} \\
\hline & No & $62.2 \%$ & $58.3 \%$ & \\
\hline \multirow{2}{*}{ A mouth sore that does not heal as a symptom of oral cancer } & Yes & $69.4 \%$ & $59.7 \%$ & \multirow{2}{*}{0.145} \\
\hline & No & $30.6 \%$ & $40.3 \%$ & \\
\hline \multirow{2}{*}{ Abnormal mass/lump in the mouth as a symptom of oral cancer } & Yes & $60.4 \%$ & $58.3 \%$ & \multirow{2}{*}{0.796} \\
\hline & No & $39.6 \%$ & $41.7 \%$ & \\
\hline \multirow{2}{*}{ White/red patch in the mouth as a symptom of oral cancer } & Yes & $37.8 \%$ & $44.6 \%$ & \multirow{2}{*}{0.303} \\
\hline & No & $62.2 \%$ & $55.4 \%$ & \\
\hline \multirow{2}{*}{ The slow change in voice quality as a symptom of oral cancer } & Yes & $33.3 \%$ & $35.3 \%$ & \multirow{2}{*}{0.790} \\
\hline & No & $66.7 \%$ & $64.7 \%$ & \\
\hline \multirow{2}{*}{ Quit tobacco use to prevent oral cancer } & Yes & $82.0 \%$ & $77.7 \%$ & \multirow{2}{*}{0.433} \\
\hline & No & $18.0 \%$ & $22.3 \%$ & \\
\hline \multirow{2}{*}{ Quit alcohol use to prevent oral cancer } & Yes & $70.3 \%$ & $63.3 \%$ & \multirow{2}{*}{0.282} \\
\hline & No & $29.7 \%$ & $36.7 \%$ & \\
\hline \multirow{2}{*}{ Avoid contact with secondhand smoke to prevent oral cancer } & Yes & $38.7 \%$ & $36.7 \%$ & \multirow{2}{*}{0.793} \\
\hline & No & $61.3 \%$ & $63.3 \%$ & \\
\hline \multirow{2}{*}{ Brush and floss your teeth twice/day to prevent oral cancer } & Yes & $54.1 \%$ & $48.2 \%$ & \multirow{2}{*}{0.375} \\
\hline & No & $45.9 \%$ & $51.8 \%$ & \\
\hline \multirow{2}{*}{$\begin{array}{l}\text { Telling your dentist when your dentures do not fit well to } \\
\text { prevent oral cancer }\end{array}$} & Yes & $22.5 \%$ & $23.0 \%$ & \multirow{2}{*}{1.00} \\
\hline & No & $77.5 \%$ & $77.0 \%$ & \\
\hline
\end{tabular}


Table 3. Cont.

\begin{tabular}{ccccc}
\hline & & & \multicolumn{2}{c}{ Alcohol } \\
\hline & & Yes & No & $p$-Value \\
\hline \multirow{2}{*}{ Education about oral cancer } & Yes & $36.0 \%$ & $38.4 \%$ & 0.792 \\
\cline { 2 - 4 } Education about human papilloma virus and oral cancer & No & $64.0 \%$ & $61.6 \%$ & \\
\cline { 2 - 4 } & No & $36 \%$ & $36.7 \%$ & $63 \%$ \\
\hline
\end{tabular}

\section{Discussion}

Oral cancer is largely considered a preventable disease and substantial public awareness and information may lead to a decrease in the number of oral cancer diseases in the population. It is quite understandable that education on oral cancer in a population is directly associated with the prognosis.

The long-term prognosis of oral cancer is not satisfactory, with a 5-year survival rate (largely of roughly $50 \%$ ), the prognosis being a consequence of various factors. Sadly, most oral cancers, even in leading countries, are discovered in advanced stages and lack of public knowledge and awareness about the signs and risk factors of oral cancer contributes to this [11].

The results of this survey showed that the level of oral cancer awareness in the North Cyprus population is not adequate. Still, the majority of the participants determined tobacco use, and more than half of the participants determined alcohol use as a risk factor. These findings resemble most studies, which also found higher public awareness of tobacco as a risk factor compared with alcohol consumption [7,11-20].

In our participants, adequate awareness of tobacco use as a risk factor for oral cancer might be correlated with high levels of education, similar to other studies. Although no statistical comparisons were made for this purpose, since $92 \%$ of the participants had a high education diploma, it can be assumed that this awareness can be due to a high education level.

Participants were aware that heavy smoking and alcohol drinking were risk factors for oral cancer, but this did not change any attitude. Health education should be performed to connect the knowledge and awareness of oral cancer together with their risk factors. It has been reported that health education could give a result in an important percentage of subjects giving up their tobacco use [15]. The behavior of tobacco use of patients could be changed by dental practitioners with the help of education about oral cancer disease risk factors.

Initial signs and symptoms of oral cancer must be recognized for early discovery of the disease, early treatment, and a positive prognosis. In our study, the knowledge of clinical symptoms of oral cancer was significantly unsatisfactory. These results resembled most of the published surveys, which also reported that public knowledge was missing for early signs of oral cancer disease. In the present study, similar to other studies regarding signs and symptoms, participants had more awareness about a mouth sore that does not heal and abnormal mass/lump in the mouth [7,11-20].

Various socioeconomic factors may contribute to public oral cancer awareness and knowledge. In the present survey study, there was a significant association between level of knowledge and awareness and gender. In our survey, female participants had significantly better awareness than males in terms of smoking and alcohol consumption, for most other survey questions there were higher mean scores but not significant, which may be caused by using educational programs in the media. These results might be because women are normally more worried about their health than men. This finding resembles other reports in terms of the association between gender and knowledge [14-18].

Public knowledge about HPV as a preventable risk factor is remarkably low, resembling other reports. For instance, Azimi et al. [7] showed 47\%, Shimpi et al. [13] reported 
only $22 \%$, and Formosa et al. [19] reported that only $23 \%$ of participants were aware of HPV infection and oral cancer diseases.

The current report showed that more than $50 \%$ of participants did not receive prior education from a primary healthcare provider about oral cancer disease. Shimpi et al. [13] found that only approximately $22 \%$ of all of their participants expressed that their healthcare providers educated them about the relation between HPV and oral cancer. Villa et al. [20] also reported that more than $85 \%$ of the participants in their survey did not get any education about oral cancer from dental physicians.

A limitation of this study includes that no question was forwarded to participants for screening the early diagnosis at-risk individuals, which the periodic screening of at-risk subjects could improve the early cancer diagnosis versus late diagnosis.

Screening for oral cancer mainly involves identifying signs and symptoms of the precancerous lesion. Efficient screening modalities that can warn patients about the possible development of the disease before any malignant progression takes place can in general improve the status of public health. Moreover, it is also important to educate the patients about the importance of routine oral examination, especially where the patient has been using tobacco or alcohol. This would not only expedite early-stage oral cancer diagnosis but also eliminate potential risk and increase a person's survival rate [21]. In the following study, this issue should also be addressed.

Another limitation of this study could be that the education status of the participants was not evaluated, since $92 \%$ of the participants had a high education diploma, thus a statistical analysis could not be made. This survey study was the first of its kind in North Cyprus to assess the public's oral cancer knowledge and awareness. However, more studies with a larger sample of participants in North Cyprus are highly recommended, including the education status of the participants.

In conclusion, our data showed that participants were generally aware of the oral cancer risk associated with tobacco, but they demonstrated lower knowledge about other risk factors. The study recommends both professional and public education of dentists to increase the level of awareness and knowledge for oral cancer diseases are necessary.

Author Contributions: Conceptualization, K.O.; methodology, M.F.; software, M.F.; formal analysis, M.F.; investigation, M.F. and S.A.; writing—original draft preparation, M.F.; writing-review and editing, S.A. and K.O.; supervision S.A. and K.O.; project administration S.A. and K.O. All authors have read and agreed to the published version of the manuscript.

Funding: This research received no external funding.

Institutional Review Board Statement: The study was conducted according to the guidelines of the Declaration of Helsinki, and approved by the Institutional Review Board (or ethics committee) of Near East University Faculty of Medicine, Ethical Com. (IRB number:2020/79-1101).

Informed Consent Statement: Informed consent was obtained from all subjects involved in the study.

Data Availability Statement: The data that support the findings of this study are available from the corresponding author upon reasonable request.

Conflicts of Interest: Authors declare no conflict of interest.

\section{References}

1. Wong, T.; Wiesenfeld, D. Oral Cancer. Aust. Dent. J. 2018, 63, S91-S99. [CrossRef] [PubMed]

2. Montero, P.H.; Patel, S.G. Cancer of the oral cavity. Surg. Oncol. Clin. N. Am. 2015, 24, 491-508. [CrossRef] [PubMed]

3. Wild, C.P.; Stewart, B.W. World Cancer Report 2014; International Agency for Research on Cancer: Lyon, France, 2014.

4. Parkin, M.; Bray, F.; Ferlay, J.; Pisani, P. Global Cancer Statistics, 2002. CA Cancer J Clin. 2005, 55, 74-108. [CrossRef] [PubMed]

5. Ahmed, N.H.M.; Naidoo, S. Oral Cancer Knowledge, Attitudes, and Practices among Dentists in Khartoum State, Sudan. J Cancer Educ. 2019, 34, 291-296. [CrossRef] [PubMed]

6. Mark, A.M. What you should know about oral cancer. J. Am. Dent. Assoc. 2016, 147, 312. [CrossRef] [PubMed]

7. Azimi, S.; Ghorbani, Z.; Tennant, M.; Kruger, E.; Safiaghdam, H.; Rafieian, N. Population Survey of Knowledge about Oral Cancer and Related Factors in the Capital of Iran. J. Cancer Educ. 2019, 34, 116-123. [CrossRef] [PubMed]

8. Kademani, D. Oral cancer. Mayo Clin. Proc. 2007, 82, 878-887. [CrossRef] [PubMed] 
9. Clarke, A.K.; Kobagi, N.; Yoon, M.N. Oral cancer screening practices of Canadian dental hygienists. Int. J. Dent. Hyg. 2018, 16, e38-e45. [CrossRef] [PubMed]

10. Scott, S.; McGurk, M.; Grunfeld, E. Patient delay for potentially malignant oral symptoms. Eur. J. Oral Sci. 2008, 116, 141-147. [CrossRef] [PubMed]

11. Hassona, Y.; Scully, C.; Abu Ghosh, M.; Khoury, Z.; Jarrar, S.; Sawair, F. Mouth cancer awareness, and beliefs among dental patients. Int. Dent. J. 2015, 65, 15-21. [CrossRef] [PubMed]

12. Al-Maweri, S.A.; Al-Soneidar, W.A.; Dhaifullah, E.; Halboub, E.S.; Tarakji, B. Oral Cancer: Awareness and Knowledge Among Dental Patients in Riyadh. J. Cancer Educ. 2017, 32, 308-313. [CrossRef] [PubMed]

13. Shimpi, N.; Jethwani, M.; Bharatkumar, A.; Chyou, P.H.; Glurich, I.; Acharya, A. Patient awareness/knowledge towards oral cancer: A cross-sectional survey. BMC Oral Health 2018, 18, 86. [CrossRef]

14. Al-Maweri, S.A.; Addas, A.; Tarakji, B.; Abbas, A.; Al-Shamiri, H.M.; Alaizari, N.A.; Shugaa-Addin, B. Public awareness and knowledge of oral cancer in Yemen. Asian Pac. J. Cancer Prev. 2014, 15, 10861-10865. [CrossRef] [PubMed]

15. Agrawal, M.; Pandey, S.; Jain, S.; Maitin, S. Oral cancer awareness of the general public in Gorakhpur City, India. Asian Pac. J. Cancer Prev. 2012, 13, 5195-5199. [CrossRef]

16. Srikanth Reddy, B.; Doshi, D.; Padma Reddy, M.; Kulkarni, S.; Gaffar, A.; Ram Reddy, V. Oral cancer awareness and knowledge among dental patients in South India. J. Cranio-Maxillofac. Surg. 2012, 40, 521-524. [CrossRef]

17. Tadbir, A.A.; Ebrahimi, H.; Pourshahidi, S.; Zeraatkar, M. Evaluation of levels of knowledge about etiology and symptoms of oral cancer in southern Iran. Asian Pac. J. Cancer Prev. 2013, 14, 2217-2220. [CrossRef]

18. Ghani, W.M.; Doss, J.G.; Jamaluddin, M.; Kamaruzaman, D.; Zain, R.B. Oral cancer awareness and its determinants among a selected Malaysian population. Asian Pac. J. Cancer Prev. 2013, 14, 17-1963. [CrossRef] [PubMed]

19. Formosa, J.; Jenner, R.; Nguyen-Thi, M.D.; Stephens, C.; Wilson, C.; Ariyawardana, A. Awareness and knowledge of oral cancer and potentially malignant oral disorders among dental patients in far North Queensland Australia. Asian Pac. J. Cancer Prev. 2015, 16, 4429-4434. [CrossRef] [PubMed]

20. Villa, A.; Kreimer, A.R.; Pasi, M.; Polimeni, A.; Cicciù, D.; Strohmenger, L.; Gherlone, E.; Abati, S. Oral cancer knowledge: A survey administered to patients in dental departments at large Italian hospitals. J. Cancer Educ. 2011, 26, 505-509. [CrossRef] [PubMed]

21. Chakraborty, D.; Natarajan, C.; Mukherjee, A. Advances in oral cancer detection. Adv. Clin. Chem. 2019, 91, 181-200. [CrossRef] [PubMed] 